ASLI QoL 2021

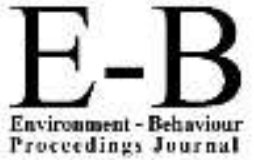

Proceeding, Juurnal

\section{AQoL2021Langkawisland}

https://www.amerabra.org; https://fspu.uitm.edu.my/cebs; https://www.emasemasresources.com/

$5^{\text {th }}$ ABRA International Conference on Quality of Life

Holiday Villa Langkawi, Langkawi Island, Malaysia, 15-16 Dec 2021

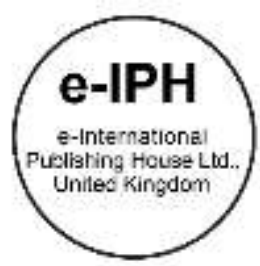

\title{
Internal Business Factors for Business Sustainability: A realistic view from sustainability managers
}

\author{
Nur Syuhada Jasni ${ }^{1}$, Haslinda Yusoff ${ }^{1}$, Purwatiningsih Lisdiono ${ }^{2}$ \\ ${ }^{1}$ Faculty of Accountancy, Universiti Teknologi MARA (UiTM) Selangor, Malaysia \\ ${ }^{2}$ Accounting Department, Faculty of Economics and Business, Universitas Indonesia \\ nursy168@uitm.edu.my, hasli229@uitm.edu.my,purwatiningsih.mba@ui.ac.id \\ Tel::+60332587494
}

\begin{abstract}
Sustainability has received a great deal of criticism, particularly the development of strategies, operationalisation and implementation of those strategies. The study aimed to understand environmental practices in business operations and identify the internal business factors that influence the success of environmental practices. Semi-structured interviews were used to gather information from Malaysian PublicListed Companies (PLCs) that significantly contributed to the advancement of sustainable development in the country. This study suggests a comprehensive set of data to investigate comparative analysis based on different industries for better insights.
\end{abstract}

Keywords: Sustainability, environmental, social, internal business factors

eISSN: 2398-4287@ 2021. The Authors. Published for AMER ABRA cE-Bs by e-International Publishing House, Ltd., UK. This is an open access article under the CC BYNC-ND license (http://creativecommons.org/licenses/by-nc-nd/4.0/). Peer-review under responsibility of AMER (Association of Malaysian Environment-Behaviour Researchers), ABRA (Association of Behavioural Researchers on Asians/Africans/Arabians) and cE-Bs (Centre for Environment-Behaviour Studies), Faculty of Architecture, Planning \& Surveying, Universiti Teknologi MARA, Malaysia.

DOI: https://doi.org/10.21834/ebpj.v6i18.3015

\subsection{Introduction}

Today, sustainability is the world's primary concern. Thus, critical attention focuses on how best businesses address this issue. The situation could be worsened if businesses, as the significant economic player, fail to consider the essential operational practices that could negatively affect humans and the environment. More businesses intend to sustain and adopt kill two birds with one stone strategy to balance business continuity and responsibility to stakeholders and the environment (Ibrahim, Hua, \& Omoola, 2019). Previous research has demonstrated that embracing sustainability improve financial performance, attracts sustainable investors, lowers operating costs, and enhances brand image and reputation. The studies also indicated that sustainability increases sales, customer loyalty, productivity and quality. All the benefits contribute to the company's market value and business sustainability (Klofsten, Urbano, \& Heaton, 2021; Mohammad \& Wasiuzzaman, 2021). Nevertheless, businesses crucially require unwavering support from top management at the microfoundations level and a proactive approach to tackle long-term risks and possibilities, ultimately leading to a stronger and sustainable stock market. Therefore, operationalisation should shift from old approaches towards sustainable innovations and business models (Geissdoerfer, Vladimirova, \& Evans, 2018). Resultantly, developing sustainable strategies that address sustainability dimensions will contribute to sustainability performance and affect the entire business performance.

Nonetheless, the inability to identify sustainability operationalisation will negatively affect businesses, including over-consumption of vulnerable resources, increasing rather than addressing sustainability concerns, a lack of competitive advantage, deteriorating company's

eISSN: 2398-4287@ 2021. The Authors. Published for AMER ABRA CE-Bs by e-International Publishing House, Ltd., UK. This is an open access article under the CC BYNCND license (http://creativecommons.org/licenses/by-nc-nd/4.0/). Peer-review under responsibility of AMER (Association of Malaysian Environment-Behaviour Researchers), ABRA (Association of Behavioural Researchers on Asians/Africans/Arabians) and CE-Bs (Centre for Environment-Behaviour Studies), Faculty of Architecture, Planning \& Surveying, Universiti Teknologi MARA, Malaysia.

DOI: https://doi.org/10.21834/ebpj.v6i18.3015 
reputation, and decreasing investor confidence (Vilanova, Lozano, \& Arenas, 2009). Interestingly, observing how a company aligns with productivity, lower costs, and provides an overall better environment for employee engagement, results in increased revenue and lower costs. If a company has the right behaviour (Tunprawat, Rugwongwan, \& Singhirunnusorn, 2017), implementing waste management (Abdul Latif \& Tengku Iskandar, 2019) and recycling activities can influence a company's culture, resulting in cost savings and a more profitable bottom line. Moreover, this study expects companies to attract new customers as more awareness is attentive to environmental practices, including product or service quality and safety.

Resultantly, empirical evidence is required at the corporate level to highlight unresolved issues by identifying the fundamental causes or challenges associated with implementing successful sustainability and addressing them accordingly (Jasni, Yusoff, Zain, Md Yusoff, \& Shaffee, 2019). The contributions may potentially assist businesses in rethinking and identifying an effective method of undertaking business that benefits internal and external stakeholders by balancing profit motives with sustainable development. Thus, sustainability issues can be alleviated before turning unmanageable while promoting macro-level (national) policies and long-term sustainable development progress. The findings are likely to increase corporate awareness, information, and preparedness to implement sustainability and overall sustainable development. Besides, this study will contribute to the literature on Asia, as previous studies were conducted in Western countries. A distinct absence of research focused on this theoretical framework has been observed in the Asian context. Additionally, this study can add value to the literature by providing information from the perspective of a developing country and complementing previous studies from developed countries.

The study aimed to explore the influence of internal business factors in effectively implementing sustainability practices, which ultimately results in the company's success. The study objectives were: 1) to understand environmental practices in business operation and 2) to identify the internal business factors in influencing the success of environmental practices. This study contributes to corporate sustainability by providing preliminary evidence that systematically integrates business prosperity's core factors.

\subsection{Literature Review}

\subsection{The Role of Internal Business Factors in Improving Environmental Practices}

Internal business factors, such as resources and capabilities, have been analysed to understand sustainability incorporation in businesses (Portillo-Tarragona, Scarpellini, Moneva, Valero-Gil, \& Aranda-Usón, 2018). Exploring resources application together with the capabilities and how they complement one another is interesting. The company owns and manages resources that are tangible or intangible. Tangible resources include factors with a financial or physical value that could contribute to economic benefits, such as financial. Conversely, intangible assets (or non-financial) factors are rarely included in a company's balance sheet, notably humans and information systems and technology (Portillo-Tarragona et al., 2018).

Hofmann, Theyel, and Wood (2012) surveyed 294 small and medium-sized manufacturers in the United States (US) and established the relationship between the underlying capabilities and environmental management practices. Specific competencies and sufficient training for employees were suggested as crucial for success, followed by a dedicated environmental manager. In summary, the study indicated that the finding could be applied to the best practices of large companies with more resources than small and medium-sized companies. Overall, ethical leadership and innovation outcomes are vital to reducing resource waste in operation and cost-effectiveness. Therefore, sustainability commitments lead to a competitive advantage beyond the traditional view of a business.

Identifying and responding to sustainability-related strategic issues is an essential process for a company. Thus, after discussing the company resources, this section presents a considerable amount of literature on optimising the company's resources by acquiring specific corporate capabilities. Attitudes and norms that serve as drivers for sustainability practices have been studied extensively (Grewatsch \& Kleindienst, 2017; Jasni \& Yusoff, 2020). Therefore, the relative importance of sustainability in corporate capabilities positively encourages the development of strategic organisational capabilities and addressing internal and external environments, which consider short-term and long-term horizons.

\subsection{Overview of Environmental Practices and Financial Performance}

Greater environmental improvement is related to environmental practices linked to the company's core business. Environmental practices integrated into processes and products are highly dependent on managers' commitment and cost control. Compliance comes with a particular cost because the company incurs environmental costs (Brooks \& Oikonomou, 2018). Operating costs would increase due to investment in purchasing equipment to meet compliance requirements for sustainable, safety, and control purposes (Barnett, 2007).

Green innovation solves waste disposal problems while positively affecting financial performance (Perez-Aleman \& Sandilands, 2008). Thus, a good supply chain leads to operational efficiency, which means fewer resources are consumed, thus, indicating less pollution (Amran, Ooi, Wong, \& Hashim, 2016). Moreover, operational efficiency requires companies to continuously improve their processes to avoid the over-consumption of vulnerable financial, natural, and social capital (Vilanova, Lozano, \& Arenas, 2009). Operational efficiency enhances sustainable development and environmental and economic performance. Conversely, strategic planning is crucial to assist the adaptation and transformation of environmental improvement and enhance internal processes of costs and resource efficiency.

Product differentiation increases customer demand and might be appealing to new customers. New customers are responsive to environmental practices, including the good quality and safety of a product or service (Bird, Hall, Momentè, \& Reggiani, 2007; Grewatsch \& Kleindienst, 2017). The product marketing strategy is vital in the marketplace, as the strategy provides opportunities to penetrate new markets due to improved environmental practices. Green products might potentially lead to customer loyalty (De Giovanni, 2012) and 
enhance the corporate image. However, the premium price of green products raises an argument, doubting the eco-friendly stance (Knight, Megicks, Agarwal, \& Leenders, 2018) that questions the products' quality rather than simply adhering to environmental guidelines.

Overall, environmental practices could integrate the processes and products that enhance financial performance. In short, a company with sound environmental practices will outperform other companies by differentiating proactive and weak environmental practices. In summary, the review and discussion above show that cost controlling, supply chains, and producing green products are the contributing factors that influence corporate environmental and financial performance.

\subsection{Methodology}

The qualitative method was used to grasp the complexity of a situation and the participants' perspectives on meaning and context. This study used a qualitative deductive approach and employed semi-structured interviews to ensure data collection consistency (Jasni \& Yusoff, 2020). The semi-structural interview is also an excellent method for grasping the complexity of a problem and the various viewpoints. During the interview, the data was delivered in audio format. The audio data was then retrieved and transcribed to text for examination.

Besides, opportunistic sampling was utilised to attract interested participants to the topic. First, fifteen experienced Malaysian Public List companies who have been listed in the Bloomberg ESG Index for over ten years are identified. They were approached to participate in this study by emailing the Head of Sustainability Managers. A week later, the researcher followed up by calling them to confirm the appointment time and location. One Executive and four Heads of the Sustainability Department volunteered to be questioned, totalling five participants. Due to time restrictions and tight schedules, ten companies declined the offer. The interviews were performed one-on-one with the participants over six months period in 2019.

This study had designed a set of initial interview questions to acquire rich information. This study's central interview question was: "What are the internal company criteria that affect practical environmental success?". The interview was followed by open-ended questions, and the interviewer could use the experience given by the participants as an example. This procedure assisted the interviewer in gaining further insight and comprehension of the participants' perceptions. Besides, using an 'active follow-up method,' questions were constantly developed and invented during the interviews, such as questions, prompts, probes, remarks, and other interventions (Wengraf, 2001). Thematic analysis was used in this study, which is an independent qualitative descriptive method that began with familiarising with data, generating initial codes, searching for themes, categorizing and naming final themes (Braun and Clarke, 2006; Hazira, Alagas, Amin, Zamzuri, \& Zairul, 2021).

\subsection{Findings}

This research attempted to examine the environmental practices in business operation and identifying the internal business factors in influencing the success of environmental practices. Two themes emerge from the analyses: i) Excellent internal processes and iii) Production of high-quality green products.

\subsection{Theme 1: Excellent internal processes}

The findings found that green efficiency is one of the factors influencing the success of environmental practices in sustainable companies, thus affecting financial results. One participant said:

"We also do things around diesel converting, moving away from diesel and petrol. So, we've actually reduced a lot of ...environmentally, the more efficient your company, there will definitely be cost savings." (P2)

Another participant explained:

"We measure but not holistically because the matter is handled by our support divisions, and they have the nationwide data. Still, not holistically because we are not disclosing non-certified AMS buildings. There are about 5,6 certified building electricity. It is not really accurate." (P3)

By commenting on the cost-saving measure in recycling initiatives, one participant said:

"Departments are encouraged to do cost-saving. They maintain things like this, such as recycling or any other $3 R$ initiative, how much is their cost-saving?" (P5)

Additionally, one participant emphasised that investment in renewable energy is costly but reduces environmental impact. Besides, focusing on reducing, reuse and recycling initiatives will potentially lead to cost-saving.

One participant commented:

"Renewable energy is expensive, but you're saving on the resources; coal, gas, and hydro. We are not burning fossil fuels; we used energy from the Sun." (P4)

The participants anticipated green efficiency to influence their financial performance positively. Recycling initiatives require a commitment to spur changes in the company culture which subsequently improve cost control and boost the company's bottom line. 
One participant also addressed the remarkable findings for beyond compliance commitment. Employees are working and planning to meet guidelines, accomplish targets, and accept that the compliance area is expanding as the business grows. As mentioned by the participant: (P4)

"As we grow the business, we expand the coverage as well... we follow the Intergovernmental Panel on Climate Change guideline."

Another participant explained:

"For example, to reduce carbon in 2020 by 40\%, then we start to have our plan, such as building our biogas plant." (P5)

One participant (P5) pointed out that companies need to equip employees with skills and upgrade the Property Plant Equipment (PPE) according to the green requirement to meet safety requirements. This view mirrored the suggestion by Brooks and Oikonomou (2018). They asserted that special equipment is needed to be sustainable (Barnett, 2007), related to safety and control. Incompliance to specific settings and PPE guidelines may potentially revoke environmental accreditation. This statement justifies this explanation:

"In terms of compliance, the contractor has to comply with our code of business conduct; they are not allowed to employ workers who don't have a permit. This part is difficult for us to control. They must follow the minimum wage rule. We must ensure they applied this to their workers. This is not only for our workers. It is quite difficult and challenging to control. So, sometimes it could be costly...PPE cost also needed to meet the safety requirements." (P5)

\subsection{Theme 2: Production of high-quality green products}

Conversely, the essence of the participants in revenue-generating activities is moving from traditional products or services by adding green elements and building a solid base of satisfied customers. Previous studies agreed that green products are gaining more loyal customers (De Giovanni, 2012) and improving corporate image. Interestingly, one participant (P5) highlighted that certification recognition could bring value-added to products sold at a premium price. The participant said:

"We sell organic fertiliser made of compost at RM5 per packet. The palm waste product is made into compost, and it becomes fertiliser. And, we could sell it, so that has monetary value, which might not be much, but at least there is something." (P5)

Another two participants alluded to the notion that they provide green products for the target customers. The participants commented: (P1)

"We build green buildings so that we attract clients who are looking for contractors that can build green buildings and have the expertise to do it."

Another participant stated:

"We know if we do this, it will put us in favour for customers, younger customers. So, we see that as a very important growth factor for millennial relevant." (P2)

Green products create new markets, and consumers are more willing to pay a higher price for green products from environmentally or socially responsible companies (Grewatsch \& Kleindienst, 2017). The innovation solves green issues, carbon emission, and pollution (Perez-Aleman \& Sandilands, 2008) and potentially increase sales and enhance financial performance. This statement is explained below:

"If we have the environmental certification, we could sell the product with a premium price to our customer." (P5)

In response to the research question, the results agreed with the findings of other studies, where the driving factors are cost control, supply chains, and green products. The qualitative result of internal business factors that influence the success of environmental practices is shown in Table 1. A possible explanation for the finding could be because cost control and supply chain are linked to green efficiency and beyond compliance commitment. In addition, the green product is also linked to activities that produce revenue. The valuable result impacts the financial result since excellent internal processes and quality green products are crucial.

Table 1. Qualitative Results of Factors that Influence the Success of Environmental Practices

\begin{tabular}{|c|c|c|c|c|}
\hline & Deductive & Codes & Categorising & Final Theme \\
\hline \multirow{3}{*}{$\begin{array}{c}\text { Internal Business } \\
\text { Factors that Influence } \\
\text { the Success of } \\
\text { Environmental Practices }\end{array}$} & \multirow{3}{*}{$\begin{array}{l}\text { Influencing factors } \\
\text { of environmental practices }\end{array}$} & $\begin{array}{l}\text { Cost-saving measure } \\
\text { incurred compliance cost }\end{array}$ & Green efficiency & Excellent internal processes \\
\hline & & $\begin{array}{c}\text { Operating with lesser } \\
\text { environmental impact, } \\
\text { planning and setting } \\
\text { targets }\end{array}$ & Beyond compliance commitment & \\
\hline & & $\begin{array}{l}\text { Generate income from } \\
\text { waste, provide green } \\
\text { products for the target } \\
\text { customer, a premium } \\
\text { price for green products }\end{array}$ & Top-line growth & $\begin{array}{l}\text { Production of high-quality } \\
\text { green products }\end{array}$ \\
\hline
\end{tabular}

\subsection{Discussion}

Based on the findings, companies are more proactive in both practices and green products. A possible explanation for the finding might be companies considering a massive amount of investment and cost. Therefore, the initiative consumes time to materialise and enhance 
financial performance. These outcomes align with previous studies. The study findings agree that green practices imply that resources are effectively used with less pollution (Amran et al., 2016). Operational effectiveness indicates cost-effective, time-saving and employee engagement with high-quality results. Besides, the combination increased revenue and lowered costs, thus, driving financial results.

Importantly, this study validated previous findings regarding internal business factors, resources and capabilities that environmental performance affects financial performance. This study aligns with Grewatsch and Kleindienst (2017) and Jasni and Yusoff (2020), establishing internal business factors as a company's competencies. Green efficiency considers investing financial resources in green technology, such as renewable and solar energy. In addition, the expertise and capabilities of human resources are utilised to handle technology effectively and help meet pre-planned targets and cost-saving initiatives. Financial resources should be expended in investing and expenses for people and PPE beyond the conformity commitment (internal capacity) to meet safety standards. In contrast, compliance concerns require strict supervision by management to prevent the revocation of specific certifications and losses on investments.

Interestingly, the sample companies increase revenue through core business operations by implementing top-line growth strategies. Beyond conventional goods, the companies invest in additional green elements, including biodegradable and biological sources. Consumers interpret green goods as good internal manufacturing processes, quality and trusted consumption to make purchasing decisions. Therefore, building a solid customer base is essential for customer satisfaction with green product purchasing decisions. These products or services generate specific market demands, which leads to higher sales and financial results.

Factors that influence environmental performance through financial performance include excellent internal processes and the development of a high-quality green product. Overall, financial, human and information systems resources were utilised. Referring to the earlier research question, excellent internal processes (internal orientation) and producing high-quality green products (external orientation) are identified as internal business factors that should be highlighted in environmental practices and business sustainability.

\subsection{Conclusion and Recommendations}

The study findings agree that the internal business factors (resources and capabilities) should focus on internal and external orientations to succeed in environmental practices for business sustainability. In the internal orientation, green practices aim to use fewer resources, which means operational productivity implies cost-effective, time-saving interaction and retain green talents. Moreover, the combination has increased sales and decreased costs, leading to financial results. Green performance has been considered when investing financially in green technologies, such as renewable and solar energy. In addition, human resource skills and capabilities are used to leverage technology efficiently and help achieve the pre-planned goals and cost-saving measures. Financial resources are spent on investment and spending on people and PPE beyond the compliance obligation commitment to comply with safety standards. Additionally, enforcement issues require strict management oversight to avoid the revocation of specific certifications and investment loss.

Interestingly, for external orientation, quality green product development is essential as consumers have recognised that green products indicate good internal production processes, good quality, and trusted consumption. Hence, buying decisions are made possible. Therefore, creating a solid customer base is necessary to meet consumer satisfaction during green product buying decisions. These products or services have developed unique market requirements that result in higher sales and financial results.

This study is also an eye-opener to companies in determining whether their resource usage is optimal, what capabilities are needed to deal with the related challenges and how to treat them as opportunities. There is no 'one-size-fits-all' solution as the process is continuous experimenting. Thus, this study provides support by assisting companies in finding the proper response and strategically making decisions. Companies' wrong responses would waste potential resources, raise more complicated issues, lose competitive advantage, and ruin companies' reputations. Additional work may be undertaken to deepen the existing examination of behavioural and management concerns in future study directions. Malaysian corporations' approach to sustainability reveals that ongoing encouragement from senior management is essential.

The companies included in this study sample are pioneers of sustainability practices with more than ten years of experience. The authors believe that the companies are in the maturity stage of sustainability evolution. Nevertheless, this study only interviewed a small number of sustainability managers and executives from the sample. Resultantly, the conclusions are confined to the participants' personal opinions and viewpoints. Only a small number of participants were interviewed due to time constraints despite more possible participants being discovered.

\section{Acknowledgement}

The authors would like to express sincere gratitude to the Research Management Centre, Universiti Teknologi MARA (UiTM), Malaysia, for funding this research project under Special Grant Scheme (600-RMC/GPK 5/3 (131/2020)).

\section{Paper Contribution to the Related Field of Study}

This study serves as a wake-up call for businesses to identify whether their resource allocation is appropriate, what capabilities are required to address associated difficulties, and how to approach them as opportunities. 


\section{References}

Abdul Latif, S., \& Tengku Iskandar, T. A. Y. (2019). Antecedents of Waste Management in the Oil and gas Industry. Retrieved November 9, 2021, from https://ebpj.eiph.co.uk/index.php/EBProceedings/article/view/1634/pdf

Amran, A., Ooi, S. K., Wong, C. Y., \& Hashim, F. (2016). Business Strategy for Climate Change: An ASEAN Perspective. Corporate Social Responsibility and Environmental Management. https://doi.org/10.1002/csr.1371

Barnett, M. L. (2007). Stakeholder influence capacity and the variability of financial returns to corporate social responsibility. Academy of Management Review. Academy of Management. https://doi.org/10.5465/AMR.2007.25275520

Bird, R., Hall, A. D., Momentè, F., \& Reggiani, F. (2007). What corporate social responsibility activities are valued by the market? Journal of Business Ethics, 76(2), 189206. https://doi.org/10.1007/s10551-006-9268-1

Braun, V., \& Clarke, V. (2006). Using thematic analysis in psychology. Qualitative Research in Psychology, 3(2), 77-101. https://doi.org/10.1191/1478088706qp0630a

Brooks, C., \& Oikonomou, I. (2018). Editorial: The effects of environmental, social and governance disclosures and performance on firm value: A review of the literature in accounting and finance. The British Accounting Review, 50(1), 1-15. https://doi.org/10.1016/J.BAR.2017.11.005

De Giovanni, P. (2012). Do internal and external environmental management contribute to the triple bottom line? International Journal of Operations and Production Management, 32(3), 265-290. https://doi.org/10.1108/01443571211212574

Geissdoerfer, M., Vladimirova, D., \& Evans, S. (2018). Sustainable business model innovation: A review. Journal of Cleaner Production. Elsevier Ltd. https://doi.org/10.1016/j.jclepro.2018.06.240

Grewatsch, S., \& Kleindienst, I. (2017). How organizational cognitive frames affect organizational capabilities: The context of corporate sustainability. Long Range Planning. https://doi.org/10.1016/j.Irp.2017.03.004

Hazira, M. N., Alagas, E. N., Amin, M., Zamzuri, N. H., \& Zairul, M. M. (2021). The best practice of marketing strategies for the Malaysian business event industry from experts' perspective. Journal of Hospitality and Tourism Insights, ahead-of-p(ahead-of-print). https://doi.org/10.1108/jhti-09-2020-0178

Hofmann, K. H., Theyel, G., \& Wood, C. H. (2012). Identifying Firm Capabilities as Drivers of Environmental Management and Sustainability Practices - Evidence from Small and Medium-Sized Manufacturers. Business Strategy and the Environment, 21(8), 530-545. https://doi.org/10.1002/bse.739

Ibrahim, I., Hua, K. P., \& Omoola, S. (2019). Corporate Environmental Responsibility in Malaysia and India: A Preliminary Analysis. Environment-Behaviour Proceedings Journal, 4(11), 195-199. https://doi.org/10.21834/E-BPJ.V4I11.1662

Jasni, N. S., Yusoff, H., Zain, M. M., Md Yusoff, N., \& Shaffee, N. S. (2019). Business strategy for environmental social governance practices: evidence from telecommunication companies in Malaysia. Social Responsibility Journal. https://doi.org/10.1108/SRJ-03-2017-0047

Jasni, N. S., \& Yusoff, H. (2020). Key Factors of Successful Corporate Environmental Practice in Selected Malaysia Public Listed Companies. Environment-Behaviour Proceedings Journal, 5(15), 19-25. https://doi.org/10.21834/ebpj.v5i15.2421

Klofsten, M., Urbano, D., \& Heaton, S. (2021). Managing intrapreneurial capabilities: An overview. Technovation, 99, 102177. https://doi.org/10.1016/j.technovation.2020.102177

Knight, H., Megicks, P., Agarwal, S., \& Leenders, M. A. A. M. (2018). Firm resources and the development of environmental sustainability among small and medium-sized enterprises: Evidence from the Australian wine industry. Business Strategy and the Environment. https://doi.org/10.1002/bse.2178

Mohammad, W. M. W., \& Wasiuzzaman, S. (2021). Environmental, Social and Governance (ESG) disclosure, competitive advantage and performance of firms in Malaysia. Cleaner $\quad$ Environmental $\quad$ Systems, $\quad$ 2, https://doi.org/10.1016/J.CESYS.2021.100015

Perez-Aleman, P., \& Sandilands, M. (2008). Building Value at the Top and the Bottom of the Global Supply Chain: MNC-NGO Partnerships. California Management Review, 51(1), 24-49. https://doi.org/10.2307/41166467

Portillo-Tarragona, P., Scarpellini, S., Moneva, J. M., Valero-Gil, J., \& Aranda-Usón, A. (2018). Classification and Measurement of the Firms' Resources and Capabilities Applied to Eco-Innovation Projects from a Resource-Based View Perspective. Sustainability, 10. https://doi.org/10.3390/su10093161

Tunprawat, C., Rugwongwan, Y., \& Singhirunnusorn, W. (2017). Product Design Enhancing Environmental Perception and Encouraging Behavioural Change towards Sustainability. Environment-Behaviour Proceedings Journal, 2(5), 355-362. https://doi.org/10.21834/E-BPJ.V2I5.659

Vilanova, M., Lozano, J. M., \& Arenas, D. (2009). Exploring the nature of the relationship between CSR and competitiveness. In Journal of Business Ethics (Vol. 87, pp. 5769). Springer. https://doi.org/10.1007/s10551-008-9812-2

Wengraf, T. (2001). Qualitative Research Interviewing: Biographic Narrative and Semi-structured Methods (1st ed.). SAGE. 